\title{
Estou me aposentando, e agora? Contribuiçóes da Terapia Ocupacional na reorganizaçáo do cotidiano
}

\author{
Julia Morais Vilela, Grasielle Silveira Tavares Paulin \\ Departamento de Terapia Ocupacional, Instituto de Ciências da Saúde, \\ Universidade Federal do Triangulo Mineiro - UFTM, Uberaba, MG, Brasil
}

\begin{abstract}
Resumo: Este estudo de natureza descritivo exploratória objetivou analisar os planos e as perspectivas que os sujeitos possuíam em relação à aposentadoria, como se constituíram a rede de suporte social, as atividades realizadas por eles cotidianamente e a importância dessas. A amostra do estudo foi composta por dez servidores da uma universidade federal do estado de Minas Gerais que participavam do PPA - Programa de Preparação para a Aposentadoria. Para a coleta de dados utilizou-se uma entrevista semiestruturada e a aplicação do Diagrama de Escolta. A análise dos dados foi feita através da Análise de Discurso de matriz peuchetiana. Dentre os resultados encontrados notou-se que as mulheres apresentaram planos mais concretos que os homens, engajando-se em outras atividades antes de aposentarem-se. Verificou-se também que a rede de suporte da maioria dos servidores reduziu-se à família e, quanto às atividades cotidianas, que a maior parte da amostra tem atualmente o trabalho como atividade principal e pretende, ao se aposentar, dedicar grande parte do seu dia ao trabalho voluntário. Conclui-se, portanto, que o fato de os sujeitos desejarem se aposentar não significa que eles estejam preparados. Sendo assim, a participação da Terapia Ocupacional no PPA possibilita traçar junto aos servidores projetos de vida que devem ser colocados em ação antes de sua aposentadoria.
\end{abstract}

Palavras-chave: Terapia Ocupacional, Envelhecimento, Aposentadoria.

\section{I'm about to retire; and now? Contributions of Occupational Therapy to the reorganization of everyday life}

\begin{abstract}
This is a descriptive exploratory study aimed at understanding the plans and prospects of individuals concerning retirement, building social support network, and activities of daily living and their importance. The study sample was composed of ten civil servants from a Federal University in Minas Gerais state who participated in the Retirement Preparation Program - PPA. Data were collected through semi-structured interviews and the application of The Convoy of Social Support. Data were analyzed by discourse analysis based on Pêcheux's conception. The results showed that women had more concrete plans than men, already engaging in other activities before retiring. It was also found that the social support network of most civil servants was restricted to the family. With respect to activities of daily living, most of the subjects in the sample currently regard their work as the main activity and intend to devote most of their time to volunteer work after retirement. We conclude that the fact that the subjects wish to retire does not mean they are prepared for it; therefore, the participation of Occupational Therapy in PPA allows civil servant to plan life projects that put them into action before their retirement.
\end{abstract}

Keywords: Occupational Therapy, Aging, Retirement.

\footnotetext{
Autor para correspondência: Grasielle Silveira Tavares Paulin, Departamento de Terapia Ocupacional, Instituto de Ciências da Saúde, Universidade Federal do Triângulo Mineiro, Rua Getúlio Guaritá, 159, $3^{\circ}$ Piso, CEP 38025-440, Uberaba, MG, Brasil, e-mail: grasiellet@yahoo.com.br
} 


\section{Introdução}

O envelhecer é um fenômeno natural da vida dos indivíduos, ou seja, é um processo geral, dinâmico, progressivo, lento e gradual, para o qual concorre uma multiplicidade de fatores genéticos, biológicos, sociais, ambientais, psicológicos e culturais característicos da pessoa e da pressão do meio ambiente. Seus efeitos são dependentes da capacidade de substituição e de compensação da pessoa e das exigências do meio (CARVALHO; NETTO, 2007).

Dessa forma, o conceito de envelhecimento bem-sucedido abrange baixo risco de doenças e de incapacidades, funcionamento físico e mental excelente e envolvimento ativo com a vida. Depende da capacidade de adaptação às mudanças físicas, emocionais e sociais. Essa habilidade é o resultado da estrutura psicológica e de condiçôes sociais construídas ao longo da vida (ASSIS, 2004).

Dentre as mudanças sociais citadas acima destaca-se a aposentadoria como um dos momentos mais decisivos na vida dos adultos maduros (FRANÇA; MENEZES; SIQUEIRA, 2012).

A aposentadoria revela uma ambivalência pois ao mesmo tempo em que é a conquista do tempo livre por meio do trabalho é também marginalizada como uma inutilidade, pela sociedade produtiva, e como um período de decadência pela concepção social que valoriza o belo, o forte, o jovem e o saudável (OLIVEIRA; TORRES; ALBUQUERQUE, 2009, p. 750).

Para Cuello e Concha (2011), muitos esperam pela aposentadoria para desfrutar de momentos de descanso e dedicação a si e sua família, porém, para outros, é inaceitável o fato de serem dispensáveis e substituíveis, o que os faz resistir a se tornarem parte da população passiva, que em nossa sociedade é sinônimo de inatividade.

Desse modo, se para alguns a aposentadoria é assimilada de forma positiva, proporcionando uma reorganização da vida, para outros é significativamente prejudicial, podendo afetar sua estrutura psíquica. Tal comprometimento pode se manifestar através de sentimentos e sintomas como ansiedade, depressão, irritabilidade e insatisfaçáo generalizada, ocasionando uma redução da qualidade de vida presente até aquele momento (RODRIGUES et al., 2005). Além disso, a aposentadoria pode repercutir indiretamente sobre o funcionamento cognitivo do idoso, já que em muitos casos o sujeito que se aposenta passa por um empobrecimento de suas redes sociais e de atividades diárias (ALVARENGA et al., 2009).
Para Both (2005), a aposentadoria é como um marco social da entrada na velhice, designando-a assim como um período socialmente inútil, por não mais se pertencer aos processos de produçáo. Desse modo a aposentadoria torna-se uma das perdas sociais mais relevantes para a vida do ser humano, em que o sujeito se sente marginalizado ao aposentar-se.

Outros estudos apontam ainda que os sujeitos que atualmente mais sofrem com a situação de aposentados são aqueles que relataram mais dificuldade para pensar e refletir acerca da aposentadoria durante o período economicamente ativo da vida (ALVARENGA et al., 2009).

Em virtude disso, o Estatuto do Idoso, Lei n. 10.741, de $1^{\circ}$ de outubro de 2003 (BRASIL, 2003), em seu capítulo VI, artigo $28^{\circ}$, inciso II, prevê a preparação dos trabalhadores para a aposentadoria, com antecedência mínima de um ano, por meio de estímulo a novos projetos sociais, conforme seus interesses, e de esclarecimento sobre os direitos sociais e de cidadania.

Portanto, algumas empresas preocupadas com a qualidade de vida de seus funcionários e pautadas na lei citada acima criaram o chamado PPA - Programa de Preparação para a Aposentadoria, — que consiste em apresentar para o funcionário condiçóes e meios para ter uma boa aposentadoria e saber desfrutá-la, ocupando seu tempo com atividades prazerosas e salutares, estimulando-o a buscar novas participaçôes nos mais diferentes grupos sociais (SILVA; ALMEIDA; MORAES, 2008).

O PPA facilita o bem-estar dos futuros aposentados, pois enfatiza os aspectos positivos e oportuniza a reflexão sobre os aspectos negativos da transição, bem como a discussão de alternativas para se lidar com eles. É a oportunidade para receber informações e para a adoção de práticas e estilos de vida que promovam a saúde. É também o momento para (re)construir o projeto de vida a curto, médio e longo prazos, priorizando os seus interesses e as atitudes que precisa tomar para realizar projetos pessoais e familiares (FRANÇA; SOARES, 2009).

No entanto, observa-se o significado e o valor que o trabalho traz para o ser humano, pois ele é parte das ocupaçôes humanas, que refletem os valores culturais, fornecem a estrutura para a vida e significado para os indivíduos, e essas atividades reúnem necessidades humanas de autocuidado, entretenimento e participação na sociedade (HOCKING, 2011).

Ainda de acordo com o autor supracitado, a ocupação é o que nos mantêm vivos e, a longo prazo, pode fornecer a atividade física, o estímulo mental 
e a interação social que precisamos para manter nossos corpos, mentes e comunidades saudáveis. Por meio da participação na ocupação, nos expressamos, desenvolvemos habilidades, experimentamos prazer e envolvimento e alcançamos tudo que acreditamos ser importante.

Dessa forma, a Terapia Ocupacional é fundamentada na compreensão de que o envolvimento em ocupaçóes estrutura a vida cotidiana e contribui para a saúde e o bem-estar. Visto que a pré-aposentadoria é um período que traz diferentes formas de pensar e ressignificar o cotidiano para os indivíduos, esta pesquisa objetivou analisar os planos e as perspectivas que os sujeitos possuíam com relação à aposentadoria, como se constituiu a rede social de suporte social, quais as atividades realizadas por eles cotidianamente e a importância delas.

\section{Métodos}

O estudo configurou-se como pesquisa do tipo descritivo exploratória. A pesquisa descritiva tem como objetivo principal descrever as características de determinada população ou fenômeno ou, então, o estabelecimento de relaçóes entre variáveis obtidas por meio da utilização de técnicas padronizadas de coletas de dados (HANDEM, 2008).

Esse tipo de pesquisa é utilizado juntamente com a exploratória, que, segundo Gil (1999), é uma pesquisa desenvolvida no sentido de proporcionar uma visão geral acerca de determinado fato. É utilizada quando o tema escolhido é pouco explorado.

O estudo foi realizado por meio do Programa de Preparação para a Aposentadoria - PPA, promovido pela Pró-Reitoria de Recursos Humanos de uma universidade federal do estado de Minas Gerais. O objetivo do PPA dessa universidade é sensibilizar os servidores quanto à importância de planejar o futuro pós-aposentadoria em função, principalmente, da manutenção da qualidade de vida. Assim, o programa é dirigido a servidores que estejam a cinco anos de se aposentar, ou seja, em fase de pré-aposentadoria, e aposentados, até dois anos após sua saída.

O programa teve início em junho de 2011 e até o mês de dezembro do mesmo ano foram realizados quatro encontros. Durante os encontros foram feitas atividades, como palestras e oficinas que abordavam diferentes temas, entre eles: a saúde e a qualidade de vida, a condição financeira, a identidade social e o cotidiano. $\mathrm{O}$ desenvolvimento dessas atividades conta com o apoio dos cursos de graduação da universidade, dentre esses, o Curso de Terapia Ocupacional, que junto à equipe organizadora contribuiu em todos os encontros, buscando um olhar direcionado ao "fazer" no cotidiano dos servidores.

Aos quatro encontros realizados em 2011 compareceram em média 60 servidores. Para a composição da amostra foi entregue aos servidores presentes no quarto encontro do Programa de Aposentadoria realizado na universidade uma carta convite para participação na pesquisa, na qual os interessados preenchiam nome, e-mail e telefone. Foram devolvidas à pesquisadora 47 cartas convite preenchidas. Após contato com os servidores, 15 demonstraram disponibilidade para participar inicialmente da pesquisa. No entanto, houve faltas e a amostra final foi composta por 10 sujeitos. Todos se encaixaram nos critérios de inclusão do estudo: ser servidor da universidade federal do estado do Minas Gerais e ter participado no mínimo de 50\% dos encontros do programa.

Utilizou-se como instrumento de pesquisa uma entrevista semiestruturada, composta de questóes abertas, e um quadro com as "áreas de ocupação humana”, que é o nome dado à ampla variedade de ocupaçóes ou atividades nas quais os indivíduos podem se envolver, no qual os entrevistados deveriam preencher a porcentagem o tempo que utilizavam em cada atividade ao longo da semana. Fazem parte das áreas de ocupação: Atividades de Vida Diária (AVDs); Atividades Instrumentais de Vida Diária (AIVDs); descanso/dormir; educação; trabalho remunerado; trabalho voluntário; brincar; lazer; e participação social (CARLETO et al., 2010).

A entrevista semiestruturada foi composta por perguntas abertas com conteúdo referente aos dados sociodemográficos (idade, gênero, estado civil, composição familiar); identificação do perfil profissional (cargo que ocupava no momento, carga horária semanal de trabalho e o tempo que faltava para a aposentadoria); importância das ocupaçóes realizadas; motivação no trabalho realizado atualmente; e estratégias e formas de enfrentamento para o aposentado. Cabe ressaltar que no final da entrevista havia uma lista dos principais termos técnicos referenciados para evitar viés no estudo.

Também foi utilizado como instrumento para a pesquisa o Diagrama de Escolta, que avalia a rede de apoio social do indivíduo, considerando as suas relaçóes sociais ao longo da vida. Dividido em duas partes, estrutural e funcional, é formado por três círculos concêntricos e hierárquicos com o indivíduo no centro, em que cada círculo representa grau distinto de proximidade afetiva e de apoio social (dar e receber). As pessoas colocadas no primeiro círculo são aquelas que apresentam maior grau de 
proximidade com o indivíduo e assim sucessivamente (COUTO; KOLLER; SOARES, 2008).

Foi realizado um estudo piloto em janeiro de 2012 no qual os instrumentos foram aplicados e verificou-se que eles atendiam aos objetivos do estudo. As entrevistas com os servidores que compuseram a amostra foram dirigidas pela pesquisadora, individualmente, também no mês de janeiro de 2012, em uma sala reservada na biblioteca da universidade, com duração média de 50 minutos, quando se deu a assinatura do Termo de Consentimento Livre e Esclarecido, baseado na Resolução n. 196/1996 (BRASIL, 1996). Os discursos foram gravados e transcritos na linguagem original dos entrevistados.

Os dados obtidos para identificação do perfil dos servidores públicos foram analisados de forma descritiva e os referentes às questóes qualitativas, pela técnica de Análise de Discurso de matriz pecheutiana, na qual busca-se compreender o sentido e nâo o conteúdo do texto, considerando a produçáo de sentidos, seja como sujeitos, seja como membros de uma determinada sociedade, parte da vida. Em suma, a Análise de Discurso visa a compreensão de como um objeto simbólico produz sentidos, como ele está investido de significância para e por sujeitos (ORLANDI, 2007).

A pesquisa foi aprovada pelo Comitê de Ética em Pesquisa da Universidade Federal do Estado de Minas Gerais sob o parecer n. 1832020.

\section{Resultados e discussão}

O perfil dos entrevistados deste estudo configurou-se da seguinte forma: sete eram do sexo feminino e três do sexo masculino, com faixa etária entre 49 e 59 anos (média $=54,4)$. Quanto ao estado civil, $80 \%$ eram casados e $20 \%$, divorciados.

Quanto ao nível de instrução e o cargo profissional que ocupavam no momento da pesquisa: eram pós-graduados (três assistentes em administração, um economista e uma técnica em assuntos educacionais); tinham o nível médio completo (um técnico em informática, uma técnica em enucleação, um pintor e um operador de xerox); e o ensino fundamental incompleto (um técnico em móveis e esquadrias).

Verifica-se a importância de compreender o cargo que esses servidores ocupam, suas motivaçóes perante a organização do trabalho e como tais aspectos podiam influenciar a preparação para aposentar-se pois, segundo Mussi (2005), o trabalho pode proporcionar prazer ou sofrimento, ser estimulante e gratificante ou maléfico à saúde física e mental do trabalhador, dependendo da situaçáo em que ocorre.
Em relação ao tempo restante para requerimento da aposentadoria, 30\% dos servidores da amostra estavam a seis meses da aposentadoria, $40 \%$ iam se aposentar dali a seis meses a um ano, $10 \%$, dali a um a dois anos e $20 \%$ dali a dois anos ou mais.

O fato de a aposentadoria estar próxima ou distante é algo que pode influenciar no discurso do sujeito, uma vez que a Análise de Discurso concebe a linguagem como mediação necessária entre o homem e realidade natural e social. Dessa forma, o perfil descrito acima se faz útil para compreender essa realidade em que o sujeito está inserido.

Traçado o perfil profissional da amostra, segue-se a análise dos dados qualitativos, sendo os resultados agrupados em três eixos de formaçóes discursivas: Planos e Perspectivas sobre a Aposentadoria; Impacto da Rede de Apoio Social no Processo da Aposentadoria; e Reflexôes sobre Ocupaçóes, Trabalho e Aposentadoria.

\subsection{Planos e perspectivas sobre aposentadoria}

Essa formação discursiva abrange como a proximidade da aposentadoria é elaborada pelo sujeito e quais são suas expectativas e planos de vida para essa nova fase.

Notou-se que os entrevistados veem a aposentadoria como algo positivo, náo apresentando nenhuma resistência a essa nova etapa da vida. Porém alguns possuem planos mais concretos, enquanto outros idealizam de forma mais subjetiva o período pós-aposentadoria. Todavia é notável nos discursos a necessidade de estarem envolvidos em outras atividades, como lazer, culturais, do cuidado pessoal, relacionadas à família e até mesmo à retomada do trabalho.

Para De Carlo e Bartalotti (2001), as atividades humanas são um conjunto de açôes que estabelecem mecanismos internos para serem realizadas. Elas são organizadoras e dão estrutura ao cotidiano, auxiliando o indivíduo na capacitação, construção da autonomia e contextualização em sua cultura e sociedade.

Para a Terapia Ocupacional, as ocupaçôes são fundamentais na vida das pessoas, bem como seu consequente valor terapêutico; daí as intervençóes que visam auxiliar indivíduos a se engajarem em atividades significativas e com finalidade no cotidiano (CARLETO et al., 2010).

Com relaçáo a esse engajamento nas atividades cotidianas observou-se que a maioria dos servidores afirma não querer vínculo empregatício após se 
aposentar, apenas um dos entrevistados referiu desejo de continuar trabalhando de forma remunerada após a aposentadoria, o que pode ser observado na frase abaixo:

"com certeza [vou continuar trabalhando], mas não com aquele pensamento, tenho que ganhar dinheiro, mas que eu vou continuar trabalhando eu vou [...] eu tenho um projeto de montar uma empresa de treinamento, capacitação e desenvolvimento humano, que é o que a gente tem feito aqui né" (S9).

Nota-se nessa fala que a manutenção do status social se sobrepóe ao aspecto financeiro, uma vez que, analisando apenas a parte financeira, não haveria grande necessidade de manter-se em um trabalho remunerado. Estudos sugerem que a retomada do trabalho ocorre pela busca do status social e do poder perdido com a desvinculação da profissão e pelo engajamento social e a retomada de suas relaçóes (MARRA et al., 2011).

Observa-se também que o sujeito 9 é o mais novo no grupo de entrevistados, o que pode justificar esse desejo, uma vez que a aposentadoria tem chegado para pessoas ainda jovens, que estáo em condiçôes de continuar trabalhando e de buscar outras atividades profissionais (FRANÇA; SOARES, 2009).

$\mathrm{Ou}$, ainda, pelo estigma de "aposentado", que pode se tornar um fardo, considerando que em nossa sociedade o termo aposentadoria remete ao conceito de velhice ou idoso.

Foi visto que a maioria dos entrevistados que apresentou planos concretos era do sexo feminino. Os planos subjetivos compuseram os discursos masculinos e esse aspecto pode ser compreendido em virtude da diferença do comportamento entre gêneros. A mulher, ao ser questionada, tende a ser mais articulada, mostrando de maneira específica e detalhada aquilo que pensa ou deseja, enquanto o homem tende a ser mais objetivo em suas respostas. Este fato pode ser compreendido segundo Parente (2006) pelas mulheres apresentarem mais cedo maior habilidade com relação a linguagem.

Observa-se que o referencial teórico descrito acima corrobora o discurso dos sujeitos do sexo masculino:

"não tenho essa preocupação, né, de não eu vô sai, que que eu vô fazê, isso aí eu não me preocupo nâo, que eu vô te muito o que fazer" (S4).

"pra fala a verdade, eu acho que eu me lembro, sabe [se referindo à aposentadoria], lembro porque tá próxima, mas não penso no sentido de preocupação não" (S2).
Em contrapartida, as mulheres apresentaram as seguintes falas:

"eu pretendo trocar com o serviço que eu faço agora, esses $60 \%$ do trabalho, e redividir nas outras atividades, por exemplo, eu já faço um curso de depilação [...] e realmente agora eu sou obrigada a ficar no trabalho porque eu dependo desse salário pra minha sobrevivência, não tem como, mesmo sabendo que as vezes eu fico estressada, querendo outra coisa" (S5).

"e eu vô fazê também, já tô fazendo, uns artesanato, não sei se vai ser coisa definitiva na minha vida, né, mas tô amando fazê artesanato, eu tenho muita habilidade com trabalhos manuais, sempre gostei, eu costuro, eu bordo [...]" (S1).

Para Marra et al. (2011), o que as mulheres vivem em sua vida profissional está sedimentado e é trazido para a construção de sua nova representação de aposentada. Assim, algumas delas conseguem elaborar melhor essa mudança e, num processo de autonomia, realizar o que estava presente no imaginário.

Convém também analisar esses discursos buscando compreender o conceito de papéis ocupacionais inserido no Modelo de Ocupação Humana, o qual aponta a ocupação humana como paradigma universal da Terapia Ocupacional. Tais papéis capacitam os indivíduos a estruturarem sua participação ocupacional e ajudam a organizar os comportamentos produtivos, fornecendo uma identidade pessoal, conferindo expectativas sociais, organizando o uso do tempo e inserindo o indivíduo na estrutura social (KIELHOFNER, 2008).

Em nossa sociedade, ao longo da vida, são atribuídos muitos papéis ao sexo feminino, como o de mãe, esposa, dona de casa, trabalhadora, enquanto para o homem, que também pode ser pai, marido, filho, é conferido o papel central de trabalhador, objetivando o "sustento" da família. Por meio dessa compreensão do desempenho de papéis de mulheres e homens na sociedade nota-se o motivo pelo qual a mulher apresenta mais facilidade na construção de novos papéis na pós-aposentadoria, sendo importante ressaltar que essa postura proativa auxilia na motivação perante as novas buscas, no processo de preparaçáo para a aposentadoria.

É válido considerar também nessa formação discursiva o tempo que falta para os servidores se aposentarem. Levando-se em consideração a análise de discurso, segundo Orlandi (2007, p. 36), "existe a necessidade de compreender o contexto em que o discurso é produzido". Nota-se que o sujeito 1 está 
a menos de seis meses de se aposentar, o que o faz pensar na aposentadoria como uma realidade muito próxima, diferindo dos sujeitos cuja aposentadoria ainda está distante.

Outro dado importante se refere ao cargo ocupado pelo servidor. Observa-se que o sujeito 5 está ocupando um cargo diferente daquele para o qual foi contratado, por causa de problemas de saúde; e em seu discurso fica explícito que o trabalho realizado atualmente não lhe traz a satisfação necessária, o que explica o fato de já buscar o engajamento em outra atividade que possa proporcionar mais motivaçáo.

\subsection{Impacto da rede de apoio social no processo de aposentadoria}

Buscou-se explorar nessa categoria quais são as relaçóes sociais que os sujeitos entrevistados possuem e como elas se dão cotidianamente, enfatizando qual o impacto dessa rede de apoio no processo de aposentadoria.

Para Lancman (2007), há uma centralidade do papel do trabalho na vida das pessoas, funcionando ele como promotor da constituição da identidade individual e, consequentemente, interferindo diretamente nas inserçôes sociais. Ele está ligado diretamente à formação das redes sociais dos indivíduos, a suas trocas afetivas e econômicas e, portanto, norteia a rotina de vida das pessoas. Para a autora, o trabalho alicerça o sentimento de pertencimento social.

No entanto, faz-se necessário a definição de apoio social que Thoits (1995) e Due et al. (1999) apud Pinto et al. (2006) definem como uma estrutura de relaçóes sociais com aspectos e fenômenos distintos. A estrutura das relaçóes sociais refere-se à organização do vínculo entre pessoas e pode ser descrita sob diferentes aspectos, como, por exemplo, a frequência de contato com vários membros de uma rede. A função compreende aspectos qualitativos e comportamentais das relaçôes sociais, sendo composta pela rede de relaçôes formais, que são relaçôes mantidas devido à posição e papéis desempenhados na sociedade, e pelas relaçôes informais, que são tidas como de maior importância pessoal e afetiva do que as relações mais especializadas e formais. São redes compostas por todos os indivíduos (família, amigos, vizinhos, colegas de trabalho, comunidade, entre outros) e pela ligação entre indivíduos com quem se tem uma relação familiar próxima ou com envolvimento afetivo.

Quanto à estrutura analisada a partir do Diagrama de Escolta, observou-se que os colegas de trabalho foram citados geralmente no segundo círculo do diagrama, enquanto o contato com os familiares, que ocorre diariamente, semanalmente e por vezes anualmente foi citado no primeiro círculo, deixando claro que o contato estabelecido diariamente com os colegas de profissão ocorreu muitas vezes em função do próprio trabalho. Nota-se, portanto, que os laços afetivos entre colegas de trabalho não se mostraram tão fortalecidos quanto os laços familiares.

Nesse sentido, para França (2002) esse é um fator positivo, uma vez que a rede de apoio, principalmente a família, tem forte influência na adaptação do indivíduo às mudanças de rotina e de papéis que ocorrem após a aposentadoria.

Por outro lado, Mucida (2009) atenta para a importância da ampliação da diversificação dos laços, uma vez que o campo social é a via pela qual o sujeito busca forma de realizar traços do seu "eu", pelas identificaçóes com os laços sociais. O ideal do "eu" oferece a possibilidade de o sujeito não se sentir perdido, destituído. É uma ferramenta indispensável para tratar as perdas e modificações advindas também da aposentadoria. Se o sujeito encontra a via dos ideais para reinscrever seu desejo, criando projetos de vida, não sentirá o desejo se esvair.

Em relação à função das relações sociais, observou-se que o apoio emocional é recebido exclusivamente por familiares, enquanto o apoio financeiro é algo ofertado, principalmente, aos filhos.

Convém citar, também, o fato de que há uma rotina preestabelecida da casa e o estreitamento do contato com o familiar (esposa/marido; filhos) se torna mais intenso. O homem, ao aposentar-se, tem mais tempo livre para ficar em casa, ele passa a viver em um ambiente que lhe é estranho, por ter-se ocupado tantos anos com o trabalho no espaço público. É preciso ter cuidado com a postura assumida pelo casal diante dessa nova realidade, pois essa perda de poder pode levar a conflitos no âmbito familiar (STUCCHI, 2003).

\subsection{Reflexões sobre ocupação, trabalho e aposentadoria}

Por fim, discutem-se nessa categoria quais ocupaçóes os sujeitos pretendem realizar com a chegada da aposentadoria, refletindo-se acerca das ocupaçôes que eles realizam atualmente.

Observou-se que sete dos entrevistados citaram o trabalho voluntário como ocupação a ser praticada futuramente, inclusive $100 \%$ dos homens, dado que diverge do estudo realizado por Duarte e Melo-Silva (2009), no qual o voluntariado foi algo 
significativamente considerado pelas mulheres participantes, em detrimento absoluto dos homens. Tal dado aponta uma das características da atividade voluntária no Brasil que, em sua maioria, é realizada por mulheres acima dos 40 anos (DUARTE; MELOSILVA, 2009).

"porque não [se] pode fica parado, ocupa[-se] o tempo com trabalho voluntário, que é uma boa coisa"(S4).

No discurso acima se vislumbra que o trabalho voluntário é uma tendência mundialmente crescente entre a população de meia-idade e mais velha, que espera encontrar no voluntariado um modo de contribuir socialmente por meio do trabalho e manter-se em níveis elevados de bem-estar coletivo, preservando o sentimento de utilidade (DENTINGER; CLARKBERG, 2002; FRANÇA, 1999; HYDE et al., 2004; PHILLIPSON, 2004; SMITH, 2004 apud DUARTE; MELO-SILVA, 2009).

Percebe-se então que o trabalho voluntário pode constituir um projeto de vida para esses sujeitos, como forma de manterem-se ativos, produtivos e inseridos na sociedade.

O segundo aspecto mais citado pelos entrevistados foi a dedicação à família, a qual Magalhães et al. (2004) definem como o retorno ao lar, em que as mulheres entrevistadas em seu estudo dizem não ter tido oportunidade de desfrutar do papel de mãe no passado, pois estavam muito envolvidas com o trabalho. Pode-se observar esse mesmo sentimento nas seguintes falas:

"sempre priorizei meu trabalho [...] corre com filho, deixa filho aqui, deixa filho ali, mas cumpria com meu horário de trabalho, agora eu vô dedicar-me à minha família" (S1).

"então você acaba esperando o momento em que você vai ter tempo, porque a minha família é grande, né, e com o tempo você vai pode se dedicar mais" (S2).

Observa-se que essas falas acima são compatíveis com o estudo feito por Marra et al. (2011), no qual eles concluem que, em sua vida profissional, as mulheres eram extremamente centradas no trabalho, com pouco tempo para si e para a família. Parte delas imaginava a aposentadoria como oportunidade de resgate desse tempo para o lazer, para cuidar de si e da família.

Em seguida, foram citadas por metade da amostra a realização de viagens e atividades ligadas ao lazer. "eu amo viajar, quando aposentá, eu vô fazê no minimo duas viagens por ano, viagens assim, não é ir ali e voltar não, 15 dias no mínimo eu vô viaja, até financeiramente eu já tô me programando"(S9).

Pode-se observar na fala acima a expectativa positiva quanto à aposentadoria. Segundo França (1999), o fato já esperado em algumas situaçôes passa a representar uma espécie de libertação da rotina e a concretizaçáo do tempo reservado ao prazer e ao lazer. Seria a expectativa da "liberdade tardia" descrita por Lehr (1999) como a vivência de sentimentos positivos com relação à aposentadoria, querendo aproveitar as experiências que não puderam alcançar devido ao envolvimento com o trabalho e a dura rotina instituída.

Analisando o exposto nessa formação discursiva, é notável que a aposentadoria seja pautada em atividades a serem realizadas cotidianamente para os sujeitos da pesquisa, o que justifica a importância da contribuição da Terapia Ocupacional nesse processo.

Dessa forma, temos que a aposentadoria é mais uma etapa da vida, e que há grandes expectativas referentes a esse novo momento. Essas expectativas, para os sujeitos da pesquisa, referem-se a desenvolver trabalhos voluntários, fazer viagens e conviver mais com a família. Tais desejos relacionam-se com a necessidade de estarem engajados em outra atividade, buscando preencher o tempo antes ocupado pelo emprego.

Diante desse universo com inúmeras possibilidades de viver essa nova fase, Mucida (2009) traz que não existe uma receita de como conduzir a pós-aposentadoria e salienta que trocar a atividade de trabalho por outra implica satisfaçôes substitutivas, que não serão mesmo como os originais. A questão é exatamente descobrir um lugar no qual o sujeito sinta-se bem e realizado. Sentir-se realizado é identificar-se com algo que escolheu. O sujeito sabe reconhecer onde se encontra de fato enlaçado, e o "segredo" é dar sustentação ao que se deseja.

\section{Conclusão}

O fato de os servidores participarem do Programa de Preparação para a Aposentadoria não alterou a concepçáo deles da aposentadoria, uma vez que apresentaram o desejo de se aposentar e veem esse fato de forma positiva em sua vida, porém isso não implica estarem totalmente preparados.

Observou-se que o engajamento em uma nova ocupação, no período ainda ativo do trabalho, facilita esse processo de adaptação, e o terapeuta ocupacional 
é o profissional apto e indicado para buscar junto ao sujeito as atividades que trarâo sentido ao seu novo projeto de vida.

Quanto ao apoio social, viu-se que as relaçôes estão restritas aos familiares. É necessário que haja uma expansão dessa rede para auxiliá-los no envelhecimento bem-sucedido e o PPA pode ser um ambiente facilitador nesse processo.

Quanto aos projetos de vida, notou-se que em muitos discursos apareceram "vontades" de realizar atividades que não foram concretizadas anteriormente em decorrência do trabalho. Desse modo, a Terapia Ocupacional, por meio das atividades, pode contribuir para despertar a busca de novos projetos, novos planos, novos sonhos, contribuindo assim para a reorganização do cotidiano.

Este estudo possibilitou diversas reflexões sobre a temática abordada, sendo possível observar que os servidores que buscaram refletir sobre esse processo conseguiram lidar melhor com essa etapa de sua vida. E notou-se que geralmente são esses indivíduos que participam das atividades propostas nos programas de preparação para aposentadoria. Dessa forma, esta pesquisa traz um questionamento que visa suscitar novas descobertas: Como trabalhar o processo de aposentadoria com os servidores que não aderem aos programas existentes nas instituições?

\section{Referências}

ALVARENGA, L. N. et al. Repercussóes da aposentadoria na qualidade de vida do idoso. Revista Escola de Enfermagem da USP, São Paulo, v. 43, n. 4, p. 796-802, 2009. http:// dx.doi.org/10.1590/S0080-62342009000400009

ASSIS, M. Promoção da saúde e envelhecimento: avaliaçáo de uma experiência no ambulatório do Núcleo de Atenção ao Idoso da UnATI/UERJ. 2004. 220 f. Tese (Doutorado em Saúde Pública)-Escola Nacional de Saúde Pública Sergio Arouca, Rio de Janeiro, 2004.

BRASIL. Ministério da Saúde. Conselho Nacional de Saúde. Resolução no 196, de 10 de outubro de 1996. Dispóe sobre diretrizes e normas regulamentadoras de pesquisas envolvendo seres humanos. Diário Oficial da União, Poder Executivo, Brasília, DF, 16 out. 1996. Disponível em: <http://conselho.saude.gov.br/resolucoes/1996/Reso196. doc> Acesso em: 7 nov. 2012.

BRASIL. Ministério da Saúde. Estatuto do idoso. Brasília: Ministério da Saúde, 2003.

BOTH, T. L. Jubilamento: o interdito de uma vida de trabalho e suas repercussōes na velhice. Revista Brasileira de Ciências e Envelhecimento Humano, Passo Fundo, v. 2, n. 1, p. 30-42, 2005.

CARLETO, D. G. S. et al. Estrutura da prática da terapia ocupacional: domínio e processo. $2^{a}$ edição. Revista Triângulo: Ensino, Pesquisa e Extensão, Uberaba, v. 3, n. 2, p. 57-147, 2010
CARVALHO, F. E. T.; NETTO, M. P. Geriatria: fundamentos, clínica e terapêutica. 2. ed. São Paulo: Atheneu, 2007.

COUTO, M. C.; KOLLER, S. H.; SOARES, P. S. Adaptação e utilizaçáo de uma medida de avaliaçáo de rede de apoio social - diagrama de escolta - para idosos brasileiros. Universitas Psychologica, Bogotá, v. 7, n. 2, p. 493-505, 2008.

CUELlO, M. A.; CONCHA, L. S. Preparation para la jubilacion em los servicios públicos de Chile. Revista Chilena de Terapia Ocupacional, Santiago, v. 11, n. 11, p. 53-64, 2011. Disponível em: <http://www. revistaterapiaocupacional.uchile.cl/index.php/RTO/ article/viewArticle/17082/17819>. Acesso em: 9 mar. 2013.

DE CARLO, M. M. R. P.; BARTALOTTI, C. Caminhos da Terapia Ocupacional. In: DE CARLO, M. M. R. P.; BARTALOTTI, C. Terapia Ocupacional no Brasil: fundamentos e perspectivas. Sáo Paulo: Plexus, 2001. p. $19-40$.

DUARTE, C. V.; MELO-SILVA, L. L. Expectativas diante da aposentadoria: um estudo de acompanhamento em momento de transição. Revista Brasileira de Orientação Profissional, São Paulo, v. 10, n. 1, p. 45-54, 2009.

FRANÇA, L. Preparação para a aposentadoria: desafios a enfrentar. In: VERAS, R. P. (Org.). Terceira idade: alternativas para uma sociedade em transição. Rio de Janeiro: Relume-Dumará, 1999. p. 11-34.

FRANÇA, L. H. F. P.; MENEZES, G. S.; SIQUEIRA, A. R. Planejamento para aposentadoria: a visão dos garis. Revista Brasileira de Geriatria e Gerontologia, Rio de Janeiro, v. 15, n. 4, p. 733-45, 2012.

FRANÇA, L. H. F. P.; SOARES, D. H. P. Preparação para a aposentadoria como parte da educação ao longo da vida. Psicologia: Ciência e Profissão, Brasília, v. 29, n. 4, p. 738-751, 2009.

FRANÇA, L. Repensando a aposentadoria com qualidade: um manual para facilitadores de programas de educação para aposentadoria em comunidades. Rio de Janeiro: UnATI, UERJ, 2002.

GIL, A. C. Métodos e técnicas de pesquisa social. São Paulo: Atlas, 1999.

HANDEM, P. C. Metodologia: interpretando autores. In: FIGUEIREDO, N. M. A. Método e metodologia na pesquisa científica. São Caetano do Sul: Yends, 2008. p. 95-102.

HOCKING, C. Contribuição da ocupação para a saúde e o bem-estar. In: NEISTADT, M. E.; CREPEAU, E. B. Willard \& Spackman: Terapia Ocupacional. 9. ed. Rio de Janeiro: Guanabara Koogan, 2011. p. 45-55.

KIELHOFNER, G. Model of human occupation: theory and application. 4. ed. Philadelphia: Lippincot Williams \& Wilkins, 2008.

LANCMAN, S. Psicodinâmica do trabalho. In: CAVALCANTI, A.; GALVÃO, C. Terapia ocupacional: fundamentação e prática. Rio de Janeiro: Guanabara Koogan, 2007. p. 271-277. 
LEHR, U. A revolução da longevidade: impacto da sociedade, na família e no indivíduo. Estudos Interdisciplinares sobre o Envelhecimento, Porto Alegre, v. 1, p. 7-36, 1999.

MAGALHÂES, M. O. et al. Padrôes de ajustamento na aposentadoria. Aletheia, Canoas, n. 19, p. 57-68, 2004.

MARRA, A. V. et al. Imaginário, subjetividade e aposentadoria feminina. Brazilian Business Review, Vitória, v. 8, n. 2, p. 119-37, 2011.

MUCIDA, A. Escrita de uma memória que não se apaga: envelhecimento e velhice. Belo Horizonte: Autêntica, 2009.

MUSSI, G. Prevalência de distúrbios osteomusculares relacionados ao trabalho (LER/DORT) em profissionais cabeleireiras de institutos de beleza de dois distritos da cidade de São Paulo. 2005. 147 f. Tese (Doutorado em Saúde Coletiva)-Universidade de São Paulo, São Paulo, 2005.

OLIVEIRA, C.; TORRES, A. R. R.; ALBUQUERQUE, E. S. Análise do Bem-Estar psicossocial de aposentados de Goiânia. Psicologia em Estudo, Maringá, v. 14, n. 4, p. 749-757, 2009.

ORLANDI, E. P. Análise de discurso: princípios e procedimentos. 7. ed. Campinas: Pontes, 2007.
PARENTE, M. A. M.P. Cognição e envelhecimento.Porto Alegre: Artmed, 2006.

PINTO, J. L. G. et al. Características do apoio social oferecido a idosos de área rural assistida pelo PSF. Ciência \& Saúde Coletiva, Rio de Janeiro, v. 11, n. 3, p. 753-764, 2006.

RODRIGUES, M. et al. A preparação para a aposentadoria: o papel do psicólogo frente a essa questão. Revista Brasileira de Orientação Profissional, São Paulo, v. 6, n. 1, p. 53-62, 2005.

STUCCHI, D. O curso da vida no contexto da lógica empresarial: juventude, maturidade e produtividade na definição da pré-aposentadoria. In: BARROS, M. L. (Org.). Velhice ou terceira idade? Estudos antropológicos sobre identidade, memória e política. 3. ed. Rio de Janeiro: FGV, 2003. p. 24-32.

SILVA, E. M.; ALMEIDA, R. M.; MORAES, L. S. PPA: Programa de Preparaçáo para Aposentadoria. In: SIMPÓSIO DE EXCELÊNCIA EM GESTÃO E TECNOLOGIA - SEGET, 5., Resende, 2008. Disponível em: <http://www.aedb.br/seget/artigos08/194_lilian_e_ elvis\%20-\%20programa\%20para\%20\%20aposentadoria. pdf> Acesso em: 27 abril 2011.

\section{Contribuição dos Autores}

Julia Morais Vilela: Participou da concepção do projeto de pesquisa e do instrumento de coleta de dados, coletou e analisou os dados e redigiu o manuscrito. Grasielle Silveira Tavares Paulin: Participou da concepçáo do projeto de pesquisa e do instrumento de coleta de dados, orientou o desenvolvimento do projeto, da coleta e da análise de dados, realizou a revisáo do texto. 